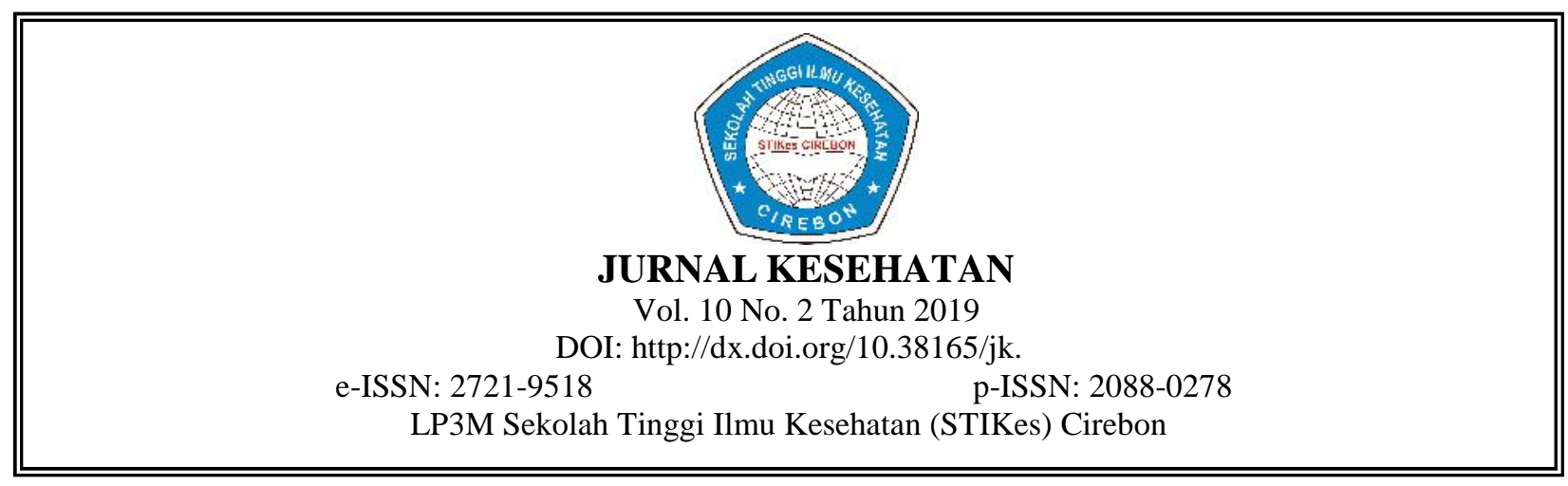

\title{
FAKTOR-FAKTOR YANG BERHUBUNGAN DENGAN KESEDIAAN BIDAN DESA UNTUK TINGGAL DI DESA
}

\author{
Yosi Yusrotul Khasanah* \\ Program Studi Kebidanan Sekolah Tinggi Ilmu Kesehatan Cirebon \\ yosikhasanah84@yahoo.com
}

\begin{abstract}
Abstrak
Strategi pembangunan kesehatan menuju Indonesia sehat 2010 mengisyaratkan bahwa pembangunan kesehatan ditujukan pada upaya menyehatkan bangsa. Indikator keberhasilannya antara lain ditentukan oleh angka mortalitas dan morbiditas, angka kematian ibu (AKI) dan angka kematian bayi (AKB). Salah satu upaya penting yang sedang ditempuh oleh pemerintah untuk mempercepat penurunan angka kematian ibu (AKI) dan angka kematian bayi (AKB) di Indonesia adalah dengan mendekatkan pelayanan kesehatan kepada masyarakat yang antara lain dilakukan melalui penempatan bidan di desa (BDD). Tujuan penelitian ini untuk mengetahui faktor-faktor yang berhubungan dengan kesediaan bidan desa untuk tetap tinggal di desa di Kabupaten Cirebon. Penelitian ini merupakan penelitian analitik Cross Sectional. Populasi pada penelitian ini adalah bidan desa yang ada di Kabupaten Cirebon sejumlah 424 orang. Teknik pengambil sample menggunakan total sampling, yang bersedia mengisi kuesioner berjumlah 353 bidan desa. Metode pengumpulan data menggunakan wawancara dan.instrumen yang digunakan adalah kuesioner, analisa data menggunakan uji chi square. Hasil penelitian ini menunujukkan variabel umur $(\mathrm{p}=0,00)$, variabel status perkawianan $(\mathrm{p}=0,00)$, variabel lama kerja $(\mathrm{p}=0,00)$, variabel lama kerja $(\mathrm{p}=0,00)$ ada hubungan dengan kesediaan bidan tinggal di desa, sedangkan variabel ketersediaaan polindes $(\mathrm{p}=0,57)$ menunjukkan tidak adanya hubungan kesediaan bidan tinggal di desa.
\end{abstract}

Kata Kunci: Faktor kesediaan bidan Desa

\begin{abstract}
The heath deveplopment strategy towards a healhty Indonesia 2010 implies that health development is aimed at making the nation healhty indicator of success are determined by mortality and morbidity and morbidity, maternal mortality $(M M R)$ and infant mortality (IMR). One of the important effort being pursued by the government to accelerate the reduction of maternal mortality (MMR) and Infant mortality (IMR) in Indonesia is to bring healh service closser to the community, which among other is done by placing midewifes in the village. The pupose of this study was to determine the factors related to willingness of village midwives to say in village in Cirebon Regency. This is cross secsional analytical study with a population of research that is village midwife in Cirebon District with a total of 242 village midewive, sampling technique using random sampling technique of 353. The results of this study indicate factors related to the willingness of village midwives to stay in the village are 25-34 years of age, marital status is married, tenure of more than 10 years, civil servant employment status, with additional income excluding salary. The result of the study addressed the age vaeriabel $(p=0,00)$ the marriage status variable $(p=0,00)$, variable leght of employment $(p=0,00)$ there was a relationship with the willingness of midewives to live in the village while the polindes availability variable $(p=0,57)$ relationship with the willingness of midewives to live in the village.
\end{abstract}

Keywords: village midewife's willingness, availability of Polindes 


\section{PENDAHULUAN}

Strategi pembangunan kesehatan menuju Indonesia sehat 2010 mengisyaratkan bahwa pembangunan kesehatan ditujukan pada upaya menyehatkan bangsa. Indikator keberhasilannya antara lain ditentukan oleh angka mortalitas dan morbiditas, angka kematian ibu (AKI) dan angka kematian bayi (AKB). Salah satu upaya penting yang sedang ditempuh oleh pemerintah untuk mempercepat penurunan angka kematian ibu (AKI) dan angka kematian bayi (AKB) di Indonesia adalah dengan mendekatkan pelayanan kesehatan kepada masyarakat yang antara lain dilakukan melalui penempatan bidan di desa (BDD). ${ }^{1}$

Angka Kematian Ibu pada tahun 1986 di Jawa Barat 686 per 100.000 kelahiran hidup dan untuk Angka Kematian Bayi 45,69 per 1000 kelahiran hidup sedangkan angka nasional pada tahun

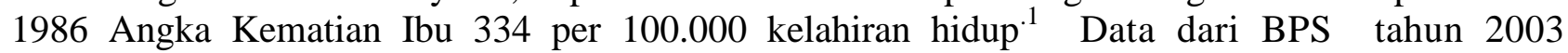
menunjukan AKB 44,36 per 1000 kelahiran hidup dan Angka Kematian Ibu 321,15 per 100.000 kelahiran hidup di propinsi Jawa Barat masih lebih tinggi dari pada Angka Kematian Ibu (AKI) Nasional yaitu 307 per 100.000 Kelahiran hidup (2002). ${ }^{2}$

Tingginya AKI di Indonesia ini dipengaruhi pula oleh belum memadainya cakupan persalinan oleh tenaga kesehatan dengan AKI. Semakin tinggi cakupan pertolongan oleh tenaga kesehatan maka akan semakin rendah AKI suatu Negara. Data SDKI 1994 menunjukan bahwa di Indonesia, 72,4\% ibu yang melahirkan di desa dan 25,2\% ibu yang melahirkan di kota masih di tolong oleh dukun, sementara belum banyak perubahan yaitu $65,3 \%$ persalinan di desa dan $23,1 \%$ di kota masih dilakukan oleh dukun. ${ }^{3}$

Angka Kematian Ibu di kabupaten Cirebon tertinggi Jawa Barat bahkan urutan ke 5 besar. Pada tahun 2008, 1000 kelahiran 66 ibu yang meninggal saat melahirkan. Pertolongan persalinan dengan tenaga kesehatan tahun 2007 mencampai 70,7, pada tahun $200872,7 .^{4}$

Keadaan ini dipengaruhi oleh terhadap kesinambungan keberadaan Bidan di desa. Tingkat drop - out Bidan desa meningkat (berkisar antara 20\%-70\%) atau rata - rata sekitar 2000 Bidan desa meninggalkan desa setiap tahunya. Berdasarkan Biro Kepegawaian Depkes RI, diketahui bahwa jumlah bidan desa terus menurun dari 62.906 Bidan desa pada tahun 2000 menjadi bekisar 39.906 Bidan desa pada bulan juli 2003. ${ }^{3}$

Baik disadari atau tidak, dampak yang dialami oleh masyarakat desa dengan berkurangnya jumlah bidan desa sangat hebat. Pertama adalah menurunnya pelayanan kesehatan masyarakat di desa karena tidak mendapatkan pelayanan kesehatan, masyarakat harus pergi ke luar desa dengan mengeluarkan ongkos transportasi yang cukup besar. Kedua karena tidak adanya bidan desa dikhawatirkan masyarakat desa akan kembali mencari pertolongan persalinan ke dukun dan target penurunan AKI menjadi semakin jauh untuk dicapai. Ketiga hilangnya fungsi bidan desa sebagai tenaga kesehatan yang berperan penting dalam upaya infestasi dini akan menyebabkan semakin mudah terjadinya lost generation yang akan menyebabkan semakin terpuruknya kualitas sumber daya manusia. ${ }^{5}$ Tujuan penelitian ini untuk mengetahui faktor-faktor yang berhubungan dengan kesediaan bidan desa untuk tetap tinggal di desa.

\section{METODE PENELITIAN}

Rancangan penelitian yang digunakan adalah penelitian analitik dengan pendekatan potong silang (cross secsional). Variabel terikat dalam penelitian ini kesediaan bidan desa tinggal di desa dan variabel bebas umur, status perkawinan, pendapatan diluar gaji, kesediaan polindes, lama kerja, status kepegawaian. Populasi dalam penelitian ini seluruh bidan yang ada di Kabupaten Cirebon sejumlah 424 bidan. Teknik pengambilan sampel menggunakan total sampling yang bersedia diwawancarai kuesioner hanya 353 bidan desa, jenis data yang dikumpulkan adalah data data primer. Data primer merupakan data yang diambil didapatkan dari responden dengan wawancara. Analisis univariat dilakukan dengan membuat tabulasi frekuensi. Analisis bivariat untuk mengetahui hubungan faktor-faktor yang berhubungan bidan untuk tinggal di desa di kabupaten Cirebon. Dengan menggunakan chi square untuk melihat adanya hubungan dilakukan dengan membandingkan $p$ value dan $\alpha=0,00$, jika $p$ value $<0,05$ maka dapat disimpulkan adanya hubungan. 


\section{HASIL PENELITIAN}

Hasil penelitian tentang variabel umur, status perkawinan, lama kerja, status kepegawaian, Pendapatan tambahan diluar gaji, ketersediaan Polindes menunujukan variabel umur kategori persentase terbesar di rentang usia 25-34 sebanyak 154 responden (43,6\%), variabel status perkawinan persentase terbesar pada kategori menikah $(87,5 \%)$, variabel lama kerja kategori $>10$ th $(60,6 \%)$, variabel status kepegawaian kategori terbesar Pegawai Negeri Sipil $(75,6 \%)$, variabel pendapat tambahan di luar gaji ada di kategori Rp.500.000-1.000.000 (32,0\%), variabel ketersediaan Polindes kategori yang terbesar tidak tersedia $(58,9 \%)$.

Tabel 1. Hubungan antara kategori umur dengan kesediaan tinggal

\begin{tabular}{|c|c|c|c|c|c|c|c|}
\hline \multirow{3}{*}{ Umur } & \multicolumn{4}{|c|}{ Kesediaan tinggal } & \multirow{3}{*}{$\begin{array}{c}\text { Jumlah } \\
\text { n }\end{array}$} & \multirow{3}{*}{$\%$} & \multirow[t]{3}{*}{ P Value } \\
\hline & \multicolumn{2}{|c|}{ Tidak bersedia } & \multicolumn{2}{|c|}{ Bersedia } & & & \\
\hline & $\mathrm{n}$ & $\%$ & $\mathrm{n}$ & $\%$ & & & \\
\hline$<25$ tahun & 11 & 20,8 & 42 & 79,2 & 53 & 100 & \\
\hline 25-34 tahun & 15 & 9,7 & 139 & 90,3 & 154 & 100 & 0,010 \\
\hline 34 tahun & 6 & 4,1 & 140 & 95,9 & 146 & 100 & \\
\hline Jumlah & 32 & 34,6 & 321 & 65,4 & 353 & 100 & \\
\hline
\end{tabular}

Berdasarkan pada tabel 1 menunjukkan bahwa responden dengan umur <25 Tahun yang bersedia tinggal desa $42(79,2 \%)$ sedangkan umur responden 34 tahun 140 (96\%) yang bersedia tinggal di desa. Hasil uji chi square diperoleh nilai $\mathrm{p}=0,010$, ini berarti terdapat hubungan yang signifikan antara umur dengan kesediaan bidan tinggal di desa.

Tabel 2. Hubungan antara kategori status perkawinan dengan kesediaan tinggal

\begin{tabular}{|c|c|c|c|c|c|c|c|}
\hline \multirow{3}{*}{ Status perkawinan } & \multicolumn{4}{|c|}{ Kesediaan tinggal } & \multirow{3}{*}{$\begin{array}{c}\text { Jumlah } \\
\text { n }\end{array}$} & \multirow{3}{*}{$\%$} & \multirow[t]{3}{*}{$\mathrm{P}$ Value } \\
\hline & \multicolumn{2}{|c|}{ Tidak bersedia } & \multicolumn{2}{|c|}{ Bersedia } & & & \\
\hline & $\mathrm{n}$ & $\%$ & $\mathrm{n}$ & $\%$ & & & \\
\hline Tidak/belum menikah & 13 & 36,1 & 23 & 63,9 & 36 & 100 & \\
\hline Pernah menikah/ janda & 0 & 0 & 8 & 100 & 8 & 100 & 0,000 \\
\hline Menikah & 19 & 6,1 & 290 & 93,9 & 309 & 100 & \\
\hline Jumlah & 32 & 9,1 & 321 & 90,9 & 353 & 100 & \\
\hline
\end{tabular}

Berdasarkan tabel 2 menunjukkan bahwa responden dengan kategori status belum menikah dan bersedia tinggal di desa $23(63,9 \%)$ sedangkan responden yang status pernikahan menikah yang bersedia tinggal di desa 290 (93,9\%). Hasil uji chi square diperoleh p=0,000. Ini berarti bahwa terdapat hubungan yang signifikan antara status perkawinan dengan kesediaan bidan tinggal di desa

Tabel 3. Hubungan antara kategori lama kerja dengan kesediaan tinggal

\begin{tabular}{|c|c|c|c|c|c|c|c|}
\hline \multirow[t]{3}{*}{ Lama kerja } & \multicolumn{4}{|c|}{ Kesediaan tinggal } & \multirow{3}{*}{$\begin{array}{c}\text { Jumlah } \\
\mathrm{n}\end{array}$} & \multirow{3}{*}{$\%$} & \multirow[t]{3}{*}{ P Value } \\
\hline & \multicolumn{2}{|c|}{ Tidak bersedia } & \multicolumn{2}{|c|}{ Bersedia } & & & \\
\hline & $\mathrm{n}$ & $\%$ & $\mathrm{n}$ & $\%$ & & & \\
\hline$<5$ Tahun & 24 & 28,2 & 61 & 71,8 & 85 & 100 & \\
\hline 5-10 Tahun & 4 & 7,4 & 50 & 92,6 & 54 & 100 & 0,000 \\
\hline$>10$ Tahun & 4 & 1,9 & 210 & 98,1 & 214 & 100 & \\
\hline Jumlah & 32 & 9,1 & 321 & 90,9 & 353 & 100 & \\
\hline
\end{tabular}

Berdasarkan pada tabel 3 menunjukkan bahwa antara lama kerja dan kesediaan tinggal di desa bahwa lama kerja > 10 tahun lebih besar sebanyak $210(98,1 \%)$ dan < dari 5 tahun sebanyak 61 
(71,8\%). Hasil uji chi square nilai $\mathrm{p}=0,000$. Ini berarti bahwa terdapat hubungan yang signifikan antara lama kerja dengan kesediaan bidan tinggal di desa.

Tabel 4. Hubungan antara kategori status kepegawaian dengan kesediaan tinggal

\begin{tabular}{|c|c|c|c|c|c|c|c|}
\hline \multirow[t]{3}{*}{ Status kepegawaian } & \multicolumn{4}{|c|}{ Kesediaan tinggal } & \multirow{3}{*}{$\begin{array}{c}\text { Jumlah } \\
\mathrm{n}\end{array}$} & \multirow{3}{*}{$\%$} & Value \\
\hline & \multicolumn{2}{|c|}{ Tidak bersedia } & \multicolumn{2}{|c|}{ Bersedia } & & & \multirow{6}{*}{0,000} \\
\hline & $\mathrm{n}$ & $\%$ & $\mathrm{n}$ & $\%$ & & & \\
\hline Bidan Harian Lepas & 8 & 32 & 17 & 68 & 25 & 100 & \\
\hline Pegawai Tidak Tetap & 17 & 27,9 & 44 & 72,1 & 61 & 100 & \\
\hline Pegawai Negeri Sipil & 7 & 2,6 & 260 & 97,4 & 267 & 100 & \\
\hline Jumlah & 32 & 9,1 & 321 & 90,9 & 353 & 100 & \\
\hline
\end{tabular}

Berdasarkan tabel 4 menunujukkan bahwa responden dengan Status Kepegawaian Bidan Harian Lepas yang bersedia tinggal di desa sebanyak 17 responden (68\%), Pegawai Tidak Tetap yang bersedia tinggal di desa sebanyak 44 responden $(72,1 \%)$ sedangkam yang Pegawai Negeri Sipil yang bersedia tinggal di desa sebanyak $260(97,4 \%)$. Hasil uji Chi Square nilai p=0.000 ini berarti bahwa terdapat hubungan yang signifikan antara kategori status Kepegawaian dengan kesediaan tinggal di desa

Tabel 5. Hubungan antara kategori pendapatan tambahan di luar gaji dengan kesediaan tinggal

\begin{tabular}{|c|c|c|c|c|c|c|c|}
\hline \multirow{3}{*}{$\begin{array}{l}\text { Pendapatan Tambahan } \\
\text { diluar gaji }\end{array}$} & \multicolumn{4}{|c|}{ Kesediaan tinggal } & \multicolumn{2}{|c|}{ Jumlah } & $\mathrm{P}$ Value \\
\hline & \multicolumn{2}{|c|}{ Tidak bersedia } & \multicolumn{2}{|c|}{ Bersedia } & \multirow[t]{2}{*}{$\mathrm{n}$} & \multirow[t]{2}{*}{$\%$} & \multirow{6}{*}{0,000} \\
\hline & $\mathrm{n}$ & $\%$ & $\mathrm{n}$ & $\%$ & & & \\
\hline$<$ Rp. 500.000 & 17 & 23 & 57 & 77 & 74 & 100 & \\
\hline Rp.500.000- 1.000 .000 & 11 & 9,73 & 102 & 90,26 & 113 & 100 & \\
\hline$>$ Rp. 1.000 .000 & 4 & 2,40 & 162 & 97,59 & 166 & 100 & \\
\hline Jumlah & 32 & 90,65 & 321 & 90,93 & 353 & 100 & \\
\hline
\end{tabular}

Berdasarkan tabel 5 menunjukkan bahwa ketersediaan bidan tinggal di desa berdasarkan kategori pendapatan tambahan diluar gaji, gaji<Rp.500.000 sebanyak 57 responden $(77 \%)$, pendapatan Rp 500.000-1.000.000 sebanyak 102 responden (90,26\%), >Rp.1.000.000 sebanyak 162 responden $(97,59 \%)$. Hasil uji chi square $\mathrm{p}=0,000$ ini berarti bahwa terdapat hubungan yang signifikan antara kategori pendapatan tambahan diluar gaji dengan kesediaan tinggal di desa.

Tabel 6. Hubungan antara kategori ketersediaan polindes dengan kesediaan tinggal

\begin{tabular}{|c|c|c|c|c|c|c|c|}
\hline \multirow{3}{*}{$\begin{array}{c}\text { Ketersediaan } \\
\text { Polindes }\end{array}$} & \multicolumn{4}{|c|}{ Kesediaan tinggal } & \multicolumn{2}{|c|}{ Jumlah } & $P$ Value \\
\hline & \multicolumn{2}{|c|}{ Tidak bersedia } & \multicolumn{2}{|c|}{ Bersedia } & \multirow{2}{*}{$\begin{array}{l}\mathrm{n} \\
\mathrm{n}\end{array}$} & $\%$ & \multirow{6}{*}{0,573} \\
\hline & $\mathrm{n}$ & $\%$ & $\mathrm{n}$ & $\%$ & & $\%$ & \\
\hline Tidak tersedia & 22 & 10,6 & 186 & 89,4 & 208 & 100 & \\
\hline Tidak Memadai & 6 & 10,5 & 51 & 89,5 & 57 & 100 & \\
\hline Memadai & 4 & 4,5 & 84 & 95,5 & 88 & 100 & \\
\hline Jumlah & 32 & 9,1 & 321 & 90,9 & 353 & 100 & \\
\hline
\end{tabular}

Berdasarkan tabel 6 menunujukkan bahwa responden dengan kategori ketersediaan Polindes dengan kesediaan tinggal di desa kategori tidak tersedia 186 (89,4\%), tidak memadai 51 (89,5\%) sedangkan kategori memadai $84(95,5 \%)$. Hasil uji chi square $\mathrm{p}=0,573$ ini berarti bahwa tidak terdapat hubungan yang signifikan antara ketersediaan polindes dengan kesediaan tinggal di desa. 


\section{PEMBAHASAN}

\section{Hubungan antara umur dengan kesediaan bidan desa untuk tetap tinggal di desa}

Berdasarkan pada tabel 1 menunjukkan bahwa responden dengan umur $<25$ Tahun yang bersedia tinggal desa $42(79,2 \%)$ sedangkan umur responden 34 tahun $140(96 \%)$ yang bersedia tinggal di desa. Hasil uji chi square diperoleh nilai $\mathrm{p}=0,010$, ini berarti terdapat hubungan yang signifikan antara umur dengan kesediaan bidan tinggal di desa. Hal ini sangat jelas karena pada usia ini menurut pengamatan peneliti semakin dewasa usia bidan desa dan semakin lama tugas di desa tersebut semakin besar peluang bidan desa tersebut untuk tetap tinggal di desa Kabupaten Cirebon. Berdasarkan hasil statistik terdapat hubungan yang bermakna antara umur berjumlah $\mathrm{p}=0,010$ tentang kesediaan bidan desa untuk tinggal di desa Kabupaten Cirebon. Sesuai dengan teori menyebutkan bahwa semakin dewasa umur seseorang semakin matang pola pemikirannya sehingga seorang bidan desa dapat melaksanakan tugasnya dengan lebih baik apabila semakin matang pola pemikirannya. $^{6}$

\section{Hubungan antara status perkawinan dengan kesediaan bidan desa untuk tetap tinggal di desa}

Berdasarkan tabel 2 menunjukkan bahwa responden dengan kategori status belum menikah dan bersedia tinggal di desa $23(63,9 \%)$ sedangkan responden yang status pernikahan menikah yang bersedia tinggal di desa 290 (93,9\%). Hasil uji chi square diperoleh $\mathrm{p}=0,000$. Ini berarti bahwa terdapat hubungan yang signifikan antara status perkawinan dengan kesediaan bidan tinggal di desa.

Hal ini serupa ditemukan pada penelitian yang dilakukan oleh Dinas Kesehatan Kalimantan Tengah 2003 yang menyimpulkan bahwa bidan desa yang sudah berkeluarga lebih betah untuk tetap tinggal di desa binaannya karena merasa mantap telah mempunyai keluarga dan rumah di desa tersebut. $^{6}$

\section{Hubungan antara lama kerja dengan kesediaan bidan desa untuk tetap tinggal di desa}

Berdasarkan pada tabel 3 menunjukkan bahwa antara lama kerja dan kesediaan tinggal di desa bahwa lama kerja >10 tahun lebih besar sebanyak $210(98,1 \%)$ dan < dari 5 tahun sebanyak 61 (71,8\%). Hasil uji chi square nilai $\mathrm{p}=0,000$. Ini berarti bahwa terdapat hubungan yang signifikan antara lama kerja dengan kesediaan bidan tinggal di desa.

Faktor lama kerja ini merupakan salah faktor yang dominan berhubungan dengan kesediaan bidan desa untuk tetap tinggal di desanya. Hal ini dapat dipahami, karena bidan desa yang telah bekerja cukup lama sudah saling mengenal masyarakat di wilayah kerjanya atau di desa binaannya, waktu pengenalan yang cukup lama membuat rasa keterikatan dan saling memiliki dapat terjalin dengan baik. ${ }^{2}$

\section{Hubungan antara status kepegawaian dengan kesediaan bidan desa untuk tetap tinggal di desa}

Berdasarkan tabel 4 menunujukkan bahwa responden dengan Status Kepegawaian Bidan Harian Lepas yang bersedia tinggal di desa sebanyak 17 responden (68\%), Pegawai Tidak Tetap yang bersedia tinggal di desa sebanyak 44 responden $(72,1 \%)$ sedangkam yang Pagawai Negeri Sipil yang bersedia tinggal di desa sebanyak 260 (97,4\%). Hasil uji chi square nilai $\mathrm{p}=0.000$ ini berarti bahwa terdapat hubungan yang signifikan antara kategori status kepegawaian dengan kesediaan tinggal di desa

Hal ini sesuai dengan teori yang menyatakan bahwa waktu pengenalan yang cukup lama membuat rasa keterikatan yang saling memiliki dapat terjalin dengan lebih baik. Pegawai yang sudah lama bertugas di desa memiliki rasa keterikatan yang tinggi dengan desa binaannya. Sebagian besar bidan desa adalah Pegawai Negeri Sipil yang sangat terikat dengan desa sesuai dengan peraturan pemerintah yang menyebutkan bahwa seorang bidan desa wajib tinggal di desa. ${ }^{7}$

Begitupun dengan bidan pegawai tidak tetap wajib tinggal di desa sesuai dengan Keputusan Menteri Kesehatan Republik Indonesia. ${ }^{8}$ Dengan demikian semakin terikat status kepegawaian 
seorang bidan terhadap desa binaannya maka semakin tinggi kesediaan bidan tersebut untuk tinggal di desa.

\section{Hubungan antara pendapatan tambahan di luar gaji dengan kesediaan bidan desa untuk tetap tinggal desa}

Berdasarkan tabel 5 menunjukkan bahwa ketersediaan bidan tinggal di desa berdasarkan kategori pendapatan tambahan diluar gaji, gaji >Rp.1.000.000 sebanyak 162 responden (97,59\%). Hasil uji chi square $\mathrm{p}=0,000$ ini berarti bahwa terdapat hubungan yang signifikan antara kategori pendapatan tambahan diluar gaji dengan kesediaan tinggal di desa.

Hal ini jelas karena tugas pokok bidan di desa tidak hanya melaksanakan pelayanan kebidanan tetapi juga harus dapat melayani pengobatan umum. ${ }^{3}$ Penelitian Sampoerno menyebutkan bidan di desa sebagai bidadari di desa yang berperan penting dalam pembangunan investasi dini yaitu penanganan kesehatan ibu hamil dan laktasi sebagai modal dasar pembangunan sumber daya manusia. ${ }^{9}$ Jadi semakin besar pendapatan tambahan di luar gaji maka semakin besar keinginan bidan desa untuk tinggal di desa binaannya.

\section{Hubungan antara ketersediaan polindes dengan kesediaan bidan desa untuk tetap tinggal di desa}

Berdasarkan tabel 6 menunujukkan bahwa responden dengan kategori ketersediaan Polindes dengan kesediaan tinggal di desa kategori tidak tersedia 186 (89,4\%), tidak memadai 51 (89,5\%) sedangkan kategori memadai 84 (95,5\%). Hasil uji chi square $\mathrm{p}=0,573$ ini berarti bahwa tidak terdapat hubungan yang signifikan antara ketersediaan polindes dengan kesediaan tinggal di desa.

Karena kriteria pondok bersalin desa adalah ${ }^{10}$ :

1. Bangunan polindes tampak bersih, salah satunya ditandai tidak adanya sampah berserakan

2. Lingkungan yang sehat, bila polindes jauh dari kandang ternak

3. Mempunyai jumlah ruangan yang cukup untuk: pemeriksaan kehamilan dan pelayanan KIA, mempunyai ruang untuk pertolongan persalinan.

4. Tempat pelayanan bersih dengan aliran udara/ventilasi yang baik terjamin.

5. Mempunyai perabotan dan alat-alat yang memadai untuk pelaksanaan pelayanan.

6. Mempunyai sarana air bersih dan jamban yang memenuhi persyaratan kesehatan.

Di Kabupaten Cirebon selama pengamatan peneliti pondok bersalin desa menyatu dengan rumah bidan desa dan sudah sesuai dengan kriteria polindes. Walau bangunan fisik tidak ada tugas pokok bidan desa seperti pemeriksaan kehamilan, memberikan pertolongan pada kegawat daruratan pada kehamilan, persalinan, masa nifas maupun bayi dan anak tetap berjalan dengan lancar tidak dijadikan sebagai hambatan.

\section{SIMPULAN}

Dari hasil penelitian tentang faktor-faktor yang berhubungan dengan kesediaan bidan desa untuk tinggal di desa di Kabupaten Cirebon didapatkan:

1. $90,9 \%$ bidan desa bersedia tinggal di desa atau desa binaanya.

2. Faktor-faktor yang secara statistik memiliki hubungan yang bermakna dengan kesediaan bidan desa untuk tetap tinggal di desa adalah umur $(\mathrm{p}=0,010)$ status perkawinan $(\mathrm{p}=0,000)$ lama kerja $(\mathrm{p}=0,000)$ status kepegawaian $(\mathrm{p}=0,000)$ dan pendapatan tambahan di luar gaji $(\mathrm{p}=0.000)$. Sedangkan ketersediaan polindes $(\mathrm{p}=0,573)$ secara statistik tidak memiliki hubungan yang bermakna dengan kesediaan bidan desa untuk tetap tinggal di desa

\section{SARAN}

Pemerintah Daerah perlu secara pro-aktif meyakinkan akan pentingnya peran bidan desa, perlunya dukungan puskesmas terhadap bidan desa, perlu mempertimbangkan pondok bersalin desa atau Polindes agar bidan desa merasa nyaman dalam melaksanakan tugasnya terutama bagi bidan desa yang baru menempati desa dan masih muda. 


\section{DAFTAR PUSTAKA}

1. Profil Dinas Kesehatan Pemerintah Propinsi Jawa barat. Kabupaten/Kota Siaga. Bandung : 2007: hal 1- 15

2. Sandra Fikawati, Wastidar musbir, Ahmad Syafiq Faktor - faktor yang berhubungan dengan kesediaan bidan desa untuk tetap bekerja dan tinggal didesa kabupaten Tanggerang propinsi Banten : jurnal Makara Kesehatan Jakarta 2003 vol 8 no.1 Hal 1-13

3. Profil Kesehatan Indonesia tahun 2007. Depatemen Kesehatan Kabupaten Cirebon 2008. [Diakses pada tanggal 12 Juli 2009]. Tersedia dari: http://www.depkes.go.id

4. __ Profil Kesehatan Indonesia Kemenkes RI Jakarta 2007

5. Departemen Kesehatan RI. Perjalanan menuju Indonesia sehat 2010. Rakernas Evaluasi Kegiatan Indonesia sehat 2010. Jakarta:Depatemen Kesehatan RI; 2005

6. Ikatan Bidan Indonesia. 50 tahun IBI Bidan menyongsong masa depan cetakan ke VII.Jakarta: pengurus pusat Ikatan Bidan Indonesia;2006:10-14

7. Keputusan Presiden Replublik Indonesia Nomor 77 Tahun 2000 tentang perubahan atas keputusan presiden no.25 Tahun 1994 Tentang pengangkatan Bidan sebagai pegawai Tidak Tetap.[Diakses pada tanggal 12 Juli 2009] Tersedia dari http://ditjenPP.kemenhumham.go.id

8. Keputusan Presiden Replublik Indonesia Nomor 23 Tahun 1994 Tentang Pengangkatan Bidan Sebagai Pegawai Tidak Tetap. [Diakses 12 Juli 2009] Tersedia dari http://m.hukumonline.com.>pusat data>node>Keppres

9. Siegel S. Statistika Non Parametrik. Jakarta : PT. Gramedia, 2007:256

10. Prasetyo B, Janah LM. Metode Penelitian Kuantitatif. Jakarta: PT. Raja Grafindo Persada; 2006;4 